\title{
Trends in pelvic inflammatory disease in England and Wales
}

\author{
NICOLA ROBINSON AND VALERIE BERAL \\ From the Epidemiological Monitoring Unit, London School of Hygiene and Tropical Medicine
}

\author{
JOHN S. A. ASHLEY
}

From the Department of Community Health, London School of Hygiene and Tropical Medicine

SUMMARY Hospital admissions for pelvic inflammatory disease increased by $8.7 \%$ a year among women aged 15-44 in England and Wales between 1966 and 1976. Acute disease was three times as frequent as chronic disease, although admissions for the chronic condition are increasing more rapidly than for the acute. Peak incidence of acute disease is at ages 20-24 and of chronic disease at ages 25-29. Divorced women had the highest rates of both forms. Single women had higher rates of acute disease than married women but the latter had higher admission rates for chronic disease.

In general, the pattern of acute disease follows that of sexually transmitted disease. The pattern of chronic disease in turn reflects the long-term effects of acute disease. The increase in chronic disease is of concern because hospital discharge rates are increasing more rapidly than for acute disease, and in 1976 one in every eight cases mentioned infertility in association with the disease.

In 1975 Weström and Mårdh' reported an increasing incidence of pelvic inflammatory disease in Sweden and noted that it paralleled an increase in sexually transmitted disease. The pattern of pelvic inflammatory disease in England and Wales is described here, with speeial reference to its relationship to sexually transmitted diseases.

Material, methods, and results

NATIONAL PUBLISHED STATISTICS

In order to assess recent trends in pelvic inflammatory disease in England and Wales, hospital admission data were examined over a period of years. Initially information was obtained from published and reference tables from the Hospital-In-Patient Enquiry (HIPE) for the years 1964 to 1977 . HIPE is a national $10 \%$ sample of hospital admissions from which can be calculated the total number of hospital cases by application of an appropriate multiplying factor. The following codes in the International Classification of Diseases (ICD) (8th revision $\left.1967^{2}\right)^{*}$ were included:

\section{Acute salpingitis and oophoritis}

613 Chronic salpingitis and oophoritis

614 Salpingitis and oophoritis, unqualified

616.0 Pelvic inflammatory disease (not otherwise specified).

*For the year 1966 equivalent codes from the 7 th revision of the $I C D^{2}$ were included.
The latter code (616.0) was traditionally used for inflammatory diseases of the parametrium but in recent years it is clear that the term has been more broadly used and includes cases which would previously have been called salpingitis and oophoritis. Therefore in this paper the term pelvic inflammatory disease is used in this modern context.

In Fig. 1, the hospital discharge rates for pelvic inflammatory disease as the principal condition in women aged 15-44 are shown, together with trends in hospital clinic attendances for gonorrhoea in women of a similar age. ${ }^{4}$ Both conditions have been increasing since 1966 but the increase has been less marked since 1971. Between 1966 and 1976 the average increase in pelvic inflammatory disease was $8.7 \%$ a yeart and in gonorrhoea $13.1 \%$ a year.

Pelvic inflammatory disease as defined above excludes admissions for chronic genitourinary gonococcal infections (ICD 098.1), a category which specifically includes gonococcal salpingitis. The published rates for this condition are small and fluctuate from year to year, averaging 0.12 per 100000 women aged $15-44$ years annually. There is no evidence of an increase in hospital admissions between 1964 and 1977. Over the same period, admissions for other forms of gonorrhoea (ICD 098 , except $098 \cdot 1$ ) in women rose consistently from 3.6

tFrom 5400 cases in 1966 to 10400 in 1976. 


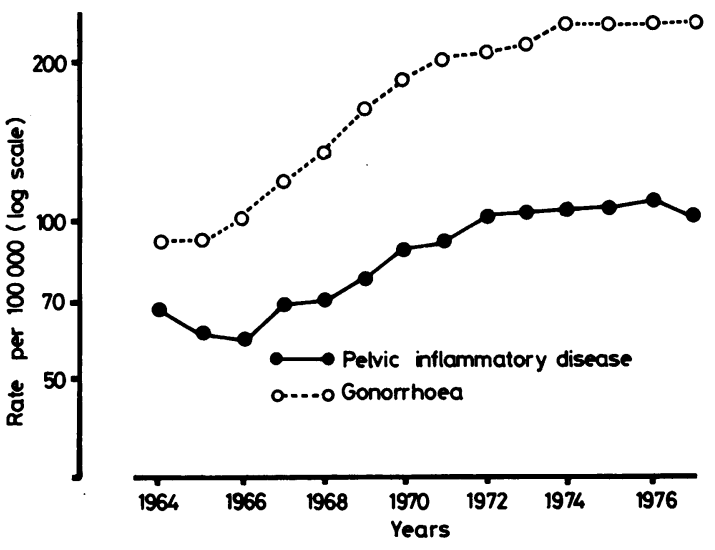

Fig. 1 Hospital discharge rates for pelvic inflammatory disease as a principal condition and attendance rates at hospital clinics for new cases of gonorrhoea: rates per 100000 women aged 15-44, England and Wales.

per 100000 in 1964 to 9.6 in 1977 . The average annual increase was $12 \cdot 8 \%$, matching closely the $13 \cdot 1 \%$ increase in clinic attendances for gonorrhoea.

\section{SPECIAL ANALYSIS}

The routinely published information relating to pelvic inflammatory disease includes it only as a principal condition, so it excludes those cases with the condition as a secondary diagnosis. Furthermore, the change in terminology referred to above often makes it impossible to distinguish acute and chronic disease on diagnostic grounds alone. Indeed, in the most recent year, $94 \%$ of cases were coded to either unspecified salpingitis (ICD 614) or pelvic inflammatory disease (ICD 616.0). In consequence, special listings for 1966, 1971, and 1976 were examined. These listings included all records with a mention of the disease as either a primary or a secondary condition. Individual cases where the disease was thought to represent a direct complication of another condition or operation were excluded from the main analyses. Examples of such exclusions were: pelvic inflammatory disease associated with a prolonged stay after hysterectomy; or after acute appendicitis where an appendectomy had been performed. The removal of a normal appendix during an admission for pelvic inflammatory disease was considered an insufficient reason for exclusion.

Each patient was classified as having either acute or chronic disease. Where no specific diagnosis of 'acute' or 'chronic' disease was recorded, classification was based on whether admission to hospital was immediate or not.
Table 1 Number of cases with mention of pelvic inflammatory disease in HIPE listings, and their adjusted assignment

\begin{tabular}{lccll}
\hline & & \multicolumn{3}{l}{ Adjusted assignment } \\
\cline { 3 - 5 } Year & $\begin{array}{l}\text { Total no. } \\
\text { in listing }\end{array}$ & $\begin{array}{l}\text { Acute } \\
\text { disease }\end{array}$ & $\begin{array}{l}\text { Chronic } \\
\text { disease }\end{array}$ & Exclusions \\
\hline 1966 & 729 & 461 & 117 & 151 \\
1971 & 1050 & 667 & 187 & 196 \\
1976 & 1405 & 819 & 345 & 241 \\
\hline
\end{tabular}

The adjusted data are given in Table 1 and displayed graphically as rates in Fig. 2, which also shows the published data and illustrates the extent to which the disease was considered to be a secondary rather than a primary condition. Acute disease rates rose from 54.5 per 100000 women aged $15-44$ in 1966 to 91.1 in 1976 and chronic rates rose from 13.8 to 38.4 during the same period. The average rise in acute disease was $6.7 \%$ a year and in chronic disease $\mathbf{1 7 \cdot 8 \%}$ a year; the total increase was $\mathbf{9} \cdot 0 \%$.

Figs. 3 and 4 show the age-specific hospital discharge rates for acute and chronic pelvic inflammatory disease respectively for 1966,1971 , and 1976. For acute disease there is a sharp peak at ages 20-24. At older ages hospital discharge rates fall abruptly. Since 1966 the increase in hospital admissions has been most marked in the younger age groups: the greatest absolute increase for acute cases

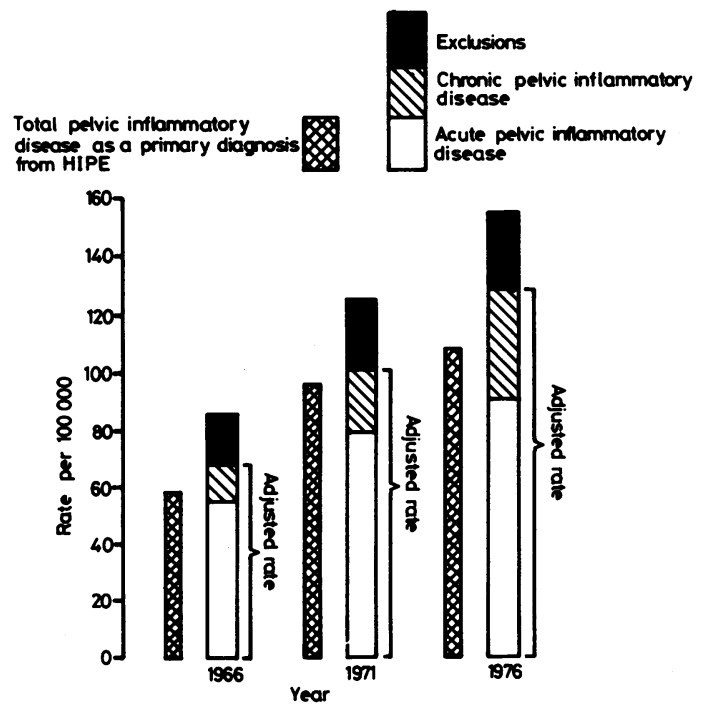

Fig. 2 Comparison of routinely published hospital discharge rates for pelvic inflammatory disease and adjusted rates after scrutiny of discharge data: rates per 100000 women aged 15-44, England and Wales. 


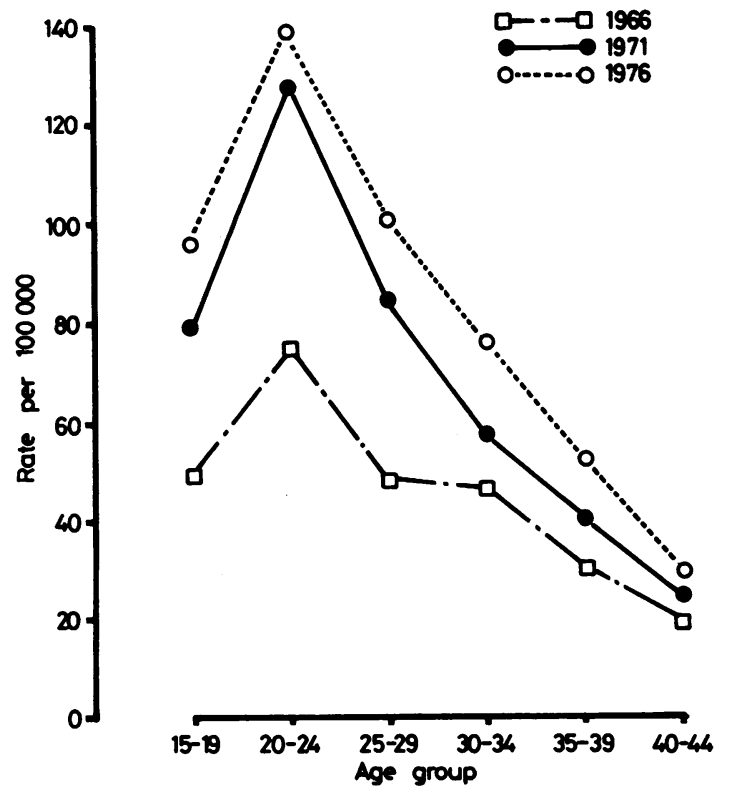

Fig. 3 Age-specific hospital discharge rates for acute pelvic inflammatory disease: rates per 100000 women, England and Wales.

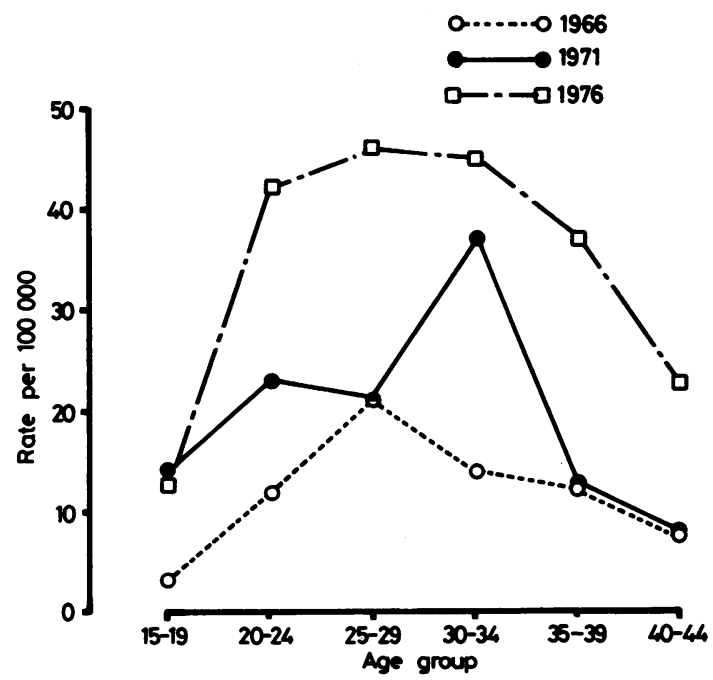

Fig. 4 Age-specific hospital discharge rates for chronic pelvic inflammatory disease: rates per 100000 women, England and Wales.

was at ages 20-24 (by 63 per 100000 women) and the greatest percentage increase was at ages 25-29 (by $11 \%$ a year). There has been a less dramatic increase in hospital admissions for acute pelvic inflammatory disease in women over the age of 40 . Age-standardised rates for 1966, 1971, and 1976 were $46.6,72 \cdot 2$, and 88.0 per 100000 women respectively.

Women admitted to hospital with chronic pelvic inflammatory disease tended to be older than those with acute disease. Peak rates for chronic disease were at ages 25-29 in 1966 and 1976, and at ages 30-34 in 1971. Since 1966 the greatest absolute increase in chronic disease has been at ages 30-34 (31 per 100000 women a year). The greatest percentage increase was at ages 20-24 (26\% a year). Age-standardised rates for 1966, 1971, and 1976 were $11.9,19.6$, and 34.7 per 100000 women respectively.

Table 2 shows the age-specific attendances at hospital clinics for gonorrhoea in women. The peak attendance rate was at ages 16-19. Between 1968 and 1977 , the attendance rate for women at hospital clinics for gonorrhoea increased by an average of $11.4 \%$ a year at ages $16-19,10.6 \%$ at ages $20-24$, and $6.3 \%$ at ages over 25.4

Table 3 shows hospital discharge rates for pelvic inflammatory disease by marital status and age. As the patterns were similar for 1966,1971 , and 1976, the data for the three years were combined. Rates of both acute and chronic disease were highest among divorced women. At all ages, married women had higher rates of chronic disease than single women. Married women aged under 20 and over 35 also had

Table 2 Age-specific rates for attendances at hospital clinics for gonorrhoea per 100000 women*

\begin{tabular}{|c|c|c|c|c|}
\hline \multirow{2}{*}{$\begin{array}{l}\text { Age groups } \\
\text { (years) }\end{array}$} & \multicolumn{4}{|l|}{ Year } \\
\hline & 1968 & 1971 & 1974 & 1977 \\
\hline $\begin{array}{l}16-19 \\
20-24 \\
25+\end{array}$ & $\begin{array}{r}255 \\
248 \\
28\end{array}$ & $\begin{array}{r}454 \\
370 \\
37\end{array}$ & $\begin{array}{r}536 \\
469 \\
42\end{array}$ & $\begin{array}{r}516 \\
486 \\
43\end{array}$ \\
\hline
\end{tabular}

"Source: Department of Health and Social Security."

Table 3 Age-specific hospital discharge rates for acute and chronic pelvic inflammatory disease per 100000 women by marital status, England and Wales (1966, 1971, and 1976 combined)

\begin{tabular}{|c|c|c|c|c|c|c|}
\hline \multirow{2}{*}{$\begin{array}{l}\text { Age } \\
\text { groups } \\
\text { (years) }\end{array}$} & \multicolumn{3}{|l|}{ Acure } & \multicolumn{3}{|c|}{ Chronic } \\
\hline & Single & Married & Divorced & Single & Married & Divorced \\
\hline $\begin{array}{l}15-19 \\
20-24 \\
25-29 \\
30-34 \\
35-39 \\
40-44\end{array}$ & $\begin{array}{r}69 \\
131 \\
102 \\
61 \\
33 \\
26\end{array}$ & $\begin{array}{r}146 \\
95 \\
68 \\
54 \\
39 \\
21\end{array}$ & $\begin{array}{r}11 \\
533 \\
145 \\
75 \\
96 \\
79\end{array}$ & $\begin{array}{r}8 \\
22 \\
25 \\
12 \\
15 \\
4\end{array}$ & $\begin{array}{l}25 \\
29 \\
29 \\
33 \\
19 \\
13\end{array}$ & $\begin{array}{r}0 \\
356 \\
31 \\
33 \\
9 \\
0\end{array}$ \\
\hline $\begin{array}{l}\text { Age- } \\
\text { standardised }\end{array}$ & 74 & 74 & 170 & 21 & 25 & 82 \\
\hline
\end{tabular}


higher rates of acute disease than single women, but between the ages of 20 and 34 single women had higher rates.

Table 4 shows hospital discharge rates for pelvic inflammatory disease by season. In 1966 peak discharges for acute disease occurred in the April-June quarter, but in 1971 and 1976 the peak occurred in July-September. For chronic disease there was no apparent seasonal pattern.

In general, cases of acute and chronic pelvic inflammatory disease increased in each hospital region of residence between 1966 and 1976 . Differences between the regions persisted over this period. Acute and chronic disease rates were highest in the Thames regions and lowest in the North for acute and in the Midlands for chronic disease.

Some of the conditions which were recorded in association with pelvic inflammatory disease are shown in Table 5. Infertility was frequently mentioned in association with chronic disease, and rarely indeed with acute. In 1966, 3.4\% of admissions for chronic disease also mentioned infertility; in $1976,13 \cdot 3 \%$ of admissions did. It would have been of interest to examine the association of pelvic inflammatory disease and use of an intrauterine device. Unfortunately the presence of a device was not coded, and its removal coded only since 1969 . In 1971 it was mentioned in $0.7 \%$ of cases and in 1976 in $1.0 \%$ of cases. The association with removal of an intrauterine device was predominantly with acute

Table 4 Hospital discharge rates for acute and chronic pelvic inflammatory disease by quarter: rates per 100000 women aged 15-44, England and Wales

\begin{tabular}{|c|c|c|c|c|c|c|}
\hline \multirow[b]{2}{*}{ Quarter } & \multicolumn{3}{|l|}{ Acute } & \multicolumn{3}{|c|}{ Chronic } \\
\hline & 1966 & 1971 & 1976 & 1966 & 1971 & 1976 \\
\hline $\begin{array}{l}\text { Jan-March } \\
\text { April-June } \\
\text { July-Sept } \\
\text { Oct-Dec }\end{array}$ & $\begin{array}{l}13 \cdot 5 \\
16 \cdot 7 \\
10 \cdot 2 \\
14 \cdot 1\end{array}$ & $\begin{array}{l}18 \cdot 1 \\
19 \cdot 0 \\
24 \cdot 1 \\
18 \cdot 1\end{array}$ & $\begin{array}{l}19 \cdot 1 \\
22.9 \\
25 \cdot 1 \\
23.9\end{array}$ & $\begin{array}{l}3.9 \\
4.5 \\
2.8 \\
2.6\end{array}$ & $\begin{array}{l}4 \cdot 9 \\
7 \cdot 2 \\
4 \cdot 7 \\
5 \cdot 5\end{array}$ & $\begin{array}{r}8 \cdot 7 \\
10 \cdot 1 \\
10 \cdot 3 \\
9 \cdot 2\end{array}$ \\
\hline
\end{tabular}

Table 5 Main conditions recorded in association with pelvic inflammatory disease

\begin{tabular}{|c|c|c|c|c|c|}
\hline \multirow[b]{3}{*}{ Year } & \multirow{3}{*}{$\begin{array}{l}\text { Total no. } \\
\text { of cases }\end{array}$} & \multicolumn{4}{|c|}{ Associated conditions } \\
\hline & & \multirow{2}{*}{$\begin{array}{l}\text { Infertility } \\
\text { No. }\end{array}$} & \multirow[b]{2}{*}{ \% } & \multicolumn{2}{|c|}{ Removal of IUD } \\
\hline & & & & No. & \% \\
\hline \multicolumn{6}{|c|}{ Acute cases } \\
\hline 1966 & 461 & $\mathbf{0}$ & 0 & $\mathbf{0}$ & $\mathbf{0}$ \\
\hline 1971 & 667 & 1 & $0 \cdot 2$ & 6 & 0.9 \\
\hline 1976 & 819 & 1 & $0 \cdot 1$ & 9 & $1 \cdot 0$ \\
\hline \multicolumn{6}{|c|}{ Chronic } \\
\hline 1966 & 117 & 4 & 3.4 & $\mathbf{0}$ & $\mathbf{0}$ \\
\hline 1971 & 187 & 17 & $9 \cdot 1$ & $\mathbf{0}$ & $\mathbf{0}$ \\
\hline 1976 & 345 & 46 & $13 \cdot 3$ & 2 & 0.6 \\
\hline
\end{tabular}

disease. Ectopic pregnancy was mentioned in no cases in 1966 , in three $(0.4 \%)$ in 1971 , and in three $(0 \cdot 3 \%)$ in 1976.

\section{Discussion}

The published, unadjusted hospital discharge rate for pelvic inflammatory disease in women aged 15-44 increased by $8.7 \%$ a year between 1966 and 1976 in England and Wales. The adjusted rates, after detailed analyses of all hospital admissions where there was any mention of pelvic inflammatory disease, show that the actual increase was similar, at 9.0\% a year. Furthermore, it demonstrates that although the relative increase in hospital admissions has been greater for chronic than for acute disease $(17.8 \%$ and $6.7 \%$ a year respectively) acute disease is on average three times more common than chronic disease and occurs at younger ages. The median age was $\mathbf{2 5}$ for acute and $\mathbf{3 0}$ for chronic cases. Both forms of the disease are especially frequent in divorced women.

It must be pointed out that the hospital admission data presented here do not differentiate between repeated admissions in the same individual and many single admissions in different people. Pelvic inflammatory disease is often recurrent, so hospital admissions cannot be used to indicate incidence of the disease. Furthermore, the severity of the disease varies considerably and hospital admissions represent only a fraction of all the disease in the community. Part of the increase in hospital admissions may be due to the fact that milder cases are now being admitted to hospitals. Data from general practitioner visits show that here, too, there has been an increase from 1.3 a year in 1955-6 to 2.0 in 1971-2 in consultation rates per 100000 women aged $15-44 .^{36}$ The increase of $3.0 \%$ a year is less marked than the increase in hospital admission rates, but the general practitioner data cover different time periods and so cannot be compared directly.

These observations are consistent with other reports. In Sweden, Weström and Mårdh ${ }^{1}$ reported that from 1955 to 1975 hospital admissions for acute pelvic inflammatory disease had increased from about 130 to 400 cases each year, that is, by approximately $10 \%$ a year. They pointed to the similarity with the upward trend in gonorrhoea. Both conditions are also increasing in England and Wales but clinic attendances for gonorrhoea have increased more rapidly than hospital discharge rates for pelvic inflammatory disease.

Better diagnostic facilities, particularly the use of the laparascope, may have contributed to the increased recognition of the disease. In 1966, 1971 , and 1976 respectively, $0 \cdot 2 \%, 1 \cdot 9 \%$, and $5 \%$ of 
acute cases and $0 \%, 11 \cdot 2 \%$, and $12.5 \%$ of chronic cases had a laparascopic procedure carried out. If these cases were excluded, the rates of acute and chronic pelvic inflammatory disease would still be increasing over time. Thus, use of the laparascope could explain only a small part of the increase in the disease.

The age-specific rates reported here are similar in pattern to those estimated by Wright and Laemmle in Atlanta for 1965. But even in 1965 the absolute rates were 10 times higher in Atlanta than they were in England and Wales in 1976. This is almost certainly because Wright and Laemmle included outpatients whereas we included inpatients only. There are no general data on outpatients in England and Wales, but information from one London-based clinic suggests that less than $10 \%$ of cases are admitted to hospital (Adler, personal communication). Also, $90 \%$ of Wright and Laemmle's population were black women in whom pelvic inflammatory disease rates are especially high (Eschenbach $e t \mathrm{al}^{\mathbf{8}}$ ). The age distribution of acute cases is more similar to that of hospital attendances for gonorrhoea in women than is chronic disease, although the peak of gonorrhoea is at younger ages than the peak of acute pelvic inflammatory disease.

The high rates of acute pelvic inflammatory disease in divorced women reported here have also been noted by Wright and Laemmle. ${ }^{7}$ In England and Wales, divorced women had overall (age-standardised) rates for acute and chronic disease of two and three times respectively those of married women. There are no data on the rate of sexually transmitted diseases in divorced women but the findings are broadly consistent with studies by Drusin $e^{a l^{9}}$ of sexually transmitted diseases in men, where divorced and separated men were reported to have 12 times the average risk of developing 'classic venereal disease' and four times the risk of other sexually transmitted diseases. The generally low rates of acute pelvic inflammatory disease in married women aged 20-34 also accord with Wright and Laemmle's findings and with observations on the incidence of sexually transmitted diseases. Except under the age of 20, married men have lower rates of gonorrhoea than single women (Haro and Patiälä ${ }^{10}$ ); also, married men have lower sexually transmitted disease rates than single men. ${ }^{\circ}$

It is clear from these analyses that acute and chronic disease differ. As would be expected, the differences are compatible with the view that chronic disease is the long-term consequence of acute disease. The latter is more frequent and occurs at younger ages. Admissions for chronic disease are increasing more rapidly than for the acute form, especially admissions for chronic disease associated with infertility. These rose from 0.5 per 100000 women aged 15-44 in 1966 to 5.1 in 1976 . The peak age-specific rates are at ages 25-29 for which in 1976 there were 12.8 discharges per 100000 women. Weström $^{11}$ has reported that $21 \%$ of women are infertile after an episode of acute pelvic inflammatory disease. We have no way of knowing whether the increase in admissions for infertility associated with chronic pelvic inflammatory disease represents an increase in its incidence or reflects a greater tendency for women with infertility to present for investigation. Overall, $96 \%$ of admissions for chronic disease and infertility had an operative procedure. The main types of operations carried out were laparoscopy (26\%), dilatation and curettage (20\%), and insufflation of Fallopian tubes (17\%). The higher rate of chronic disease in married women may reflect the fact that they are more likely to seek treatment of long-term consequences, such as infertility. On the other hand, it may reflect different hospital admission policies for single and married people.

Wiesner and Holmes ${ }^{12}$ reported a similar seasonal incidence of gonorrhoea and pelvic inflammatory disease in the.USA - both were most frequent in the third quarter of each year and least frequent in the first. In England and Wales, reports of attendances for sexually transmitted diseases at hospital clinics were most frequent in the third quarter of each year (Higgins, personal communication) which is consistent with 1971 and 1976 hospital admissions for acute pelvic inflammatory disease.

In general, the increase in acute pelvic inflammatory disease seems to parallel that of sexually transmitted disease. Trends over time and age distributions are compatible and the seasonal patterns and relationships with marital status are similar. Thus the current epidemic of sexually transmitted diseases may well be a major factor contributing to the increase in acute pelvic inflammatory disease. Whether gonorrhoea itself or some other specific infections are the causative organisms cannot be assessed from these data-although it is interesting how rarely 'gonococcal salpingitis' is reported and that there has been no apparent increase in that specific diagnosis since 1964. Cultures for gonococcal organisms are, if anything, more commonly performed now than in the $1960 \mathrm{~s}$. The increasing interest in other organisms responsible for the disease has led to a variety of organisms being cultured from inflamed Fallopian tubes $^{13}$ and these organisms are likely to be contributory to the increase in acute pelvic inflammatory disease. We examined the hospital admission data for other factors which might be contributing to the increase in acute disease. Use of 
the intrauterine device has been linked with an increased risk of pelvic inflammatory disease. ${ }^{14}$ 15 Unfortunately presence of the device was not coded but its removal is. It is thus impossible to know to what extent use of the device contributed to the increase in acute pelvic inflammatory disease.

The pattern of chronic pelvic inflammatory disease is consistent with its being a consequence of acute disease. Clinically, chronic pelvic inflammatory disease is a heterogeneous group of conditions ranging from definite cases, with a history of previous acute disease and histological or laparoscopic evidence of chronic tubal infection, to ill-defined cases where the only symptoms may be vague lower abdominal pain and pelvic tenderness. Unfortunately it is at present impossible to distinguish between the definite and the ill-defined cases. In the future more specific disease categories are provided for by the 9th revision of the International Classification of Diseases, ${ }^{16}$ and more detailed analyses will then be possible. Nevertheless, the increase in hospital discharge rates is of concern since these are increasing more rapidly than those for acute disease and a high proportion of cases are associated with infertility. It is important for more to be known about the clinical presentation and conditions associated with chronic disease: it may well become an increasingly common cause of morbidity among women in the future.

We thank the Office of Population Censuses and Surveys for the use of their data and Professor M. Adler and Mrs. B. Higgins for help and advice.

Reprints .from Dr. Valerie Beral, Department of Medical Statistics and Epidemiology, London School of Hygiene and Tropical Medicine, Keppel Street, London WC1E 7HT.

\section{References}

${ }^{1}$ Weström L, Mårdh PA. Acute salpingitis. Aspects of the aetiology, diagnosis and prognosis. In: Danielsson $D$, ed. Proceedings of the symposium on general infections and their complications. Stockholm: Almquist and Wiksell International, 1975: 157-67.

${ }^{2}$ World Health Organisation. International classification of diseases, 8th revision. Geneva: WHO, 1967.

3 World Health Organisation. International classification of diseases, 7th revision. Geneva: WHO, 1957.

-Department of Health and Social Security. Annual reports of the Chief Medical Officer, 1968-70 and 1971-77. On the State of the Public Health. London: HMSO, 1969-71 and 1972-78.

${ }^{5}$ Office of Population Censuses and Surveys. Morbidity statistics from general practice. Studies on medical and population subjects no. 14. London: HMSO, 1958.

- Office of Population Censuses and Surveys. Morbidity statistics from general practice. Second national study 1970-71. Studies on medical and population subjects no. 26. London: HMSO, 1974.

${ }^{7}$ Wright NH, Laemmle P. Acute pelvic inflammatory disease in an indigent population. Am J Obstet Gynecol 1968; 101: 979-90.

- Eschenbach DA, Harnisch JP, Holmes KK. Pathogenesis of acute pelvic inflammatory disease. Role of contraception and other risk factors. Am J Obstet Gynecol 1977; 128: 838-50.

${ }^{\circ}$ Drusin LM, Magagna J, Yano K, Ley AB. An epidemiologic study of sexually transmitted diseases on a university campus. Am J Epidemiol 1974; 100: 8-19.

${ }^{10} \mathrm{Härö} \mathrm{AS,} \mathrm{Pätiälä} \mathrm{R.} \mathrm{Epidemiology} \mathrm{of} \mathrm{gonorrhoea} \mathrm{in}$ Finland from 1953 to 1955 . Br J Vener Dis 1957; 33: 70-7.

"Weström L. Effect of acute pelvic inflammatory disease on fertility. Am J Obstet Gynecol 1975; 121: 707-13.

12 Wiesner. PJ, Holmes KK. Current view of the epidemiology of sexually transmitted diseases in the United States. In: Danielsson D, ed. Proceedings of the symposium on general in fections and their complications. Stockholm: Almquist and Wiksell International, 1975: 14-24.

${ }^{13}$ Eschenbach DA, Buchanan TM, Pollock HH et al. Polymicrobial aetiology of acute pelvic inflammatory disease. N Engl J Med 1975; 293: 166-71.

${ }^{14}$ Targum SD, Wright NH. Association of the intrauterine device and pelvic inflammatory disease: a retrospective pilot study. Am J Epidemiol 1974; 100: 262-71.

${ }^{15}$ Weström L, Bengtsson LP, Mårdh PA. The risk of pelvic inflammatory disease among women using intrauterine devices as compared to non-users. Lancet 1976; ii: $221-4$.

${ }^{10}$ World Health Organisation. International classification of diseases, 9th revision. Geneva: WHO, 1977. 